the convent's unsympathetic confessorpriest give some hint of the suppressed passions that raged under the black veil and rough brown linen habit of the Franciscan order of the Poor Clares. Indeed, the regime of the community - the sisters were perpetually barefoot, forced to sleep on bare boards and woken at midnight for hours of prayer - are harsh enough for any Ulsterman's nightmare of Rome.

One hard fact above all shines from this book. Until the twentieth century, the female revolved around the male. Women did what they were told, even if it meant, as in the case of both of Galileo's daughters, being shorn of their hair in pre-adolescence and sequestered for life to accommodate their father's social and economic circumstances.

Galileo's reasoning was clear. His children were illegitimate. Living for many years as professor of mathematics at the University of Padua, he never married his young mistress, the mother of his three children, because she was of lower social station. Burdened already by the responsibility of finding a dowry for his sister, he could offer none to his two daughters. For the unmarriageable, the convent offered the only economic recourse. Galileo, nonetheless, did persuade his Medici patron to legitimize his 13-year-old son, Vincenzio Galilei, a favour sweetened by the grant to the boy of a pension for life. Vincenzio went on to law school and marriage to a young woman with a substantial dowry.

The chance to explain Galileo's work brings out Sobel's science-writing best. She explains how Galileo perfected the Dutch spyglass, and with his telescope discovered the moons of Jupiter and the mountains of the Moon, and how, in 1613, he obediently put aside astronomy for eight years after the Holy Fathers passed an edict against anyone denying the scriptural truth that the heavens are immutable and the Earth is at the centre of the Universe. Her mechanical descriptions are as felicitous for Galileo's compass as for the clocks of the eighteenth-century Joseph Harrison in Longitude.

She is excellent, too, on the history of the Europe of the Thirty Years' War, and of the bubonic plague that swept the continent, isolating city from city, invading Italy from Germany in 1629. When Sobel comes to the unworldly, gifted daughter, however, a pofaced reverence takes over. A certain stiltedness was perhaps inevitable, as Maria Celeste's letters are couched in effusive phrases such as "Most Illustrious Lord Father", which could apply either to the scientist or the Saviour.

The book's design unfortunately contrives for a faux prayer-book tone. The preciousness of using Suor Maria Celeste's enlarged sloping Renaissance script for chapter headings is exacerbated by the author's indulgence in churchy archaisms, such as "in the Year of Our Lord" to specify certain dates. There is also an embarrassing dedication, in which the name of Galileo Galilei is coupled with that of the author's own father, Samuel Hillel Sobel, MD.

These irritants, however, are secondary to a powerful reminder that the past is another country, in which people think and behave under conditions unimaginable today. The sea of faith, as Matthew Arnold reminded the increasingly rationalist late-nineteenth century, was once full at the flood. Religion held together the moral universe of Galileo and his daughter. From the evidence presented in this scrupulous contribution to the history of science, neither felt a trace of anger against the system that governed their minds and bodies.

Brenda Maddox is at 9 Pitt Street, London W8 4NX, UK.

\section{A rival for the Burgess Shale}

\section{The Chengjiang Fauna: \\ Exceptionally Well-Preserved Animals from 530 Million Years Ago}

by Hou Xianguang, Jan Bergström,

Wang Haifeng, Feng Xianghong

and Chen Ailin

Yunnan Science and Technology Press: 1999. 170 pp. $£ 40, \$ 70$ (pbk)

\section{Douglas Palmer}

More than 120 species of fossils, including the oldest-known vertebrates recently described by D-G. Shu et al., have already been described from Chengjiang in Yunnan Province, southwest China. The rock strata of this 530-million-year-old, early-Cambrian marine deposit are set to rival the Burgess Shale, British Columbia's World Heritage Site of similar age, which has yielded around 150 species.

Two-hundred or so colour photographs illustrate 12 new species and 72 other members of The Chengjiang Fauna. Altogether, they are one of the world's most important hoards of fossils. They open a fascinating window on the remarkable diversity of early Cambrian animals and their adaptation to an unexpectedly wide variety of niches close to a level seabed.

Although the text is in Chinese, there is a brief English summary and very useful bibliography to the primary literature. Hou Xianguang, the senior author, first found the deposit in 1984. As he records, it was 3 o'clock on the afternoon of 1 July when he broke open a piece of mudstone to reveal a beautifully preserved specimen of the arthropod Naraoia, previously known only from the Burgess Shale.

Interestingly, Cambrian strata and fossils

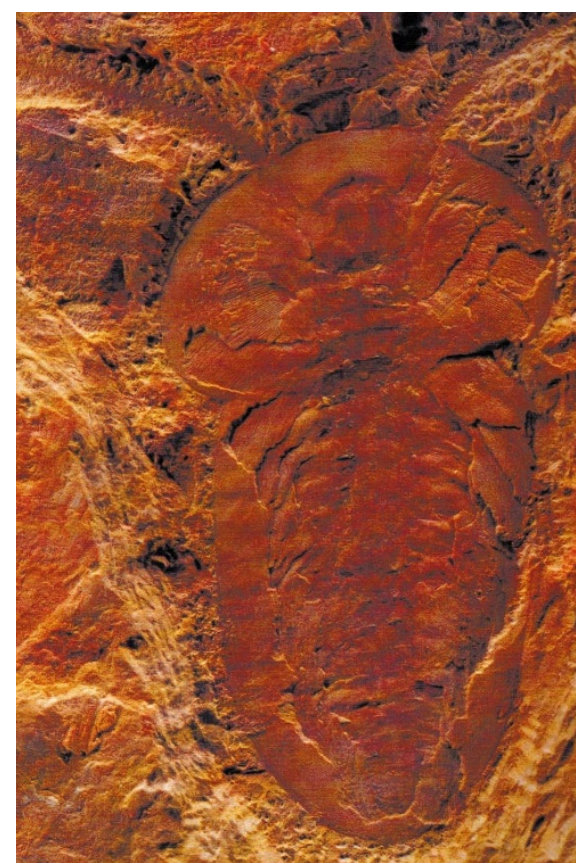

A window on diversity: Naraoia longicaudata, one of Chengjiang's rich hoard of fossils.

from this province of China were first found by the French geologists Jacques Deprat and Henri Mansuy in 1916. But they did not find the Chengiiang deposit. If they had, the débâcle over 'planted' fossils, which led to Deprat's dismissal from the Geological Survey of Indochina in 1920, may never have happened (see Nature 389, 688; 1997).

Douglas Palmer is at 31 Mawson Road, Cambridge CB1 2DZ, UK.

The book can be ordered from Hou Xianguang Nanjing Institute of Geology \& Palaeontology, Academia Sinica, Chi-Ming-Ssu, Nanjing 210008, People’s Republic of China ( $£ 10$ (\$17) postage \&packing).

\section{Problem squares and virtuous circles}

\section{A History of Algorithms: From the} Pebble to the Microchip edited by Jean-Luc Chabert

Springer: 1999. 524 pp. \$59.95, £39.95 (pbk) Jeremy Gray

There is, at times, a deep division of intellectual labour in science. Some people formulate problems in the conceptual terms of a particular theory, some express the problems in mathematical terms, and some people solve them. It may be that one person does all three things, or that three protagonists are needed, none of whom communicates fully with the others. Each may nurture their own expertise while downplaying that of the others. In productive subjects, the solutions generate further 
problems and the exchange forms a virtuous circle. This rich book, which reaches, as its subtitle indicates, from prehistory to the present day, illuminates the problemsolving side - the production of precise numbers, tables and functions.

Producing solutions can be challenging in a variety of ways. Sometimes a quick, accurate method is required, as in long multiplication. The defeat of the abacus users by those who favoured calculation with numbers is an oft-told tale, and it is told again here. Another example is the inversion of matrices and the solution of linear equations. This topic was taken up by Karl Friedrich Gauss and, despite the tremendous speed of modern computers, it remains an issue because of the size of the problems we wish to tackle, such as weather forecasting.

Problems involving squares became, centuries later, quadratic equations. The solution involves square roots, so how are

\section{Science in culture}

\section{Quicker than the eye}

"Now you see it. Now you don't," claimed the censured Peugeot car advertisements.

Martin Kemp

In the era of the photographic image, blur has become an almost universal way to denote motion faster than the eye can discern. But the actual observation of what came to be called the 'persistence of vision' long predated photography. The Islamic philosopher Ibn al-Haytham (Alhazen) described the phenomenon clearly during the Middle Ages, and Leonardo da Vinci in the early sixteenth century drew our attention to the blurred spokes of a spinning wheel, the circle left in the air by a whirling firebrand and the apparent "rods" of falling rain. The motif of blur first dramatically entered painting more than 100 years after Leonardo's account with the radiant spokes in Diego Velázquez's Las Hilanderas (The Spinners).

We are now so accustomed to the conventions of blurred motion in photography that an image-maker can assume that we will have no difficulty in knowing what a streaky impression signifies. We are also familiar with the reverse convention of frozen motion, stilled by 'instantaneous' photography. Famous examples are the coronet splashes, first captured by the physicist Arthur Worthington in 1909 and commercially exploited by Harold Edgerton at Strobe Alley in the middle of the century (see Nature 396, 633; 1998). What happens when the apparently contradictory conventions are brought together in a single image?

This combination is precisely what the improbably named advertising agency Euro RSCG Wnek Gosper exploited in the two images devised in their "Now You See It. Now You Don't" campaign for the Peugeot 206 GTI car. The advertisements were withdrawn after an adverse ruling from the Advertising Standards Authority that they "gave the impression that the car was being driven at high speed" and "could encourage" irresponsibly fast driving. My intention here is not to stir already troubled waters, but to look at the remarkably sophisticated viewing modes that are needed if the images are to operate at full power.

One image, the less perceptually complex, shows a road stretching into the far distance. In the left foreground, a puddle has been splashed

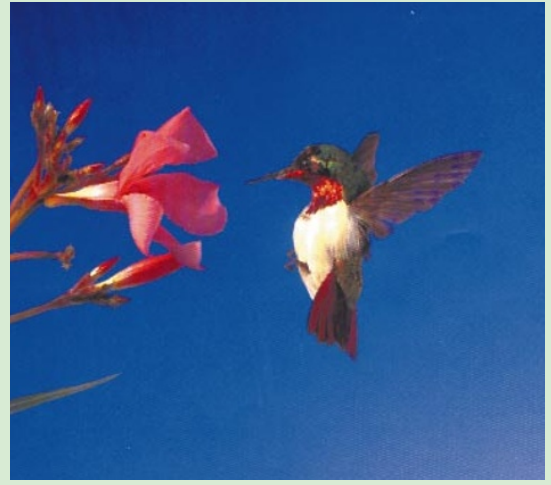

A hummingbird - no car - and speed.

upwards to form a jagged trough frozen in time and space. No car is visible. The perceptual implication is that the car has disappeared in the trice that the splash remains in the air provided the audience is one that assumes cars drive on the left side of the road.

The second image smears a red blur across the rightmost portion of a road shown parallel to the plane of the picture. On the extreme left, a bird with a rapier-sharp beak is suspended in front of the open calyx of a pink flower. It would be possible to interpret the image simply as an attractive picture of a grand landscape — with the blur of a fast vehicle on the open road. But its full effect depends on our recognizing the bird as a hummingbird and knowing that its wings vibrate so incredibly rapidly when hovering (at 50-80 beats per second) that they would appear blurred in all but a high-speed photographic process. Where has the car gone in that tiny instant?

Taken together, the computer-processed photographic pictures used in the advertisements assume very sophisticated levels of visual knowledge in the target population (readers of the national press). They also show how agencies now expect us to work readily with the remarkably elliptical approach adopted in much of today's advertising, in which the literal image of the product has been superseded by visual implication and juxtaposition of an often surrealist kind. The viewing habits required are not just those of the photographic era, but also of the age of the digitally manipulated picture. Martin Kemp is in the Department of the History of Art, University of Oxford, Oxford OX1 2BE, UK. they to be found? Cubic equations led to cube roots, more complicated equations to more complicated approximation methods. Arabic mathematicians were innovative in this area. Nasir al-Din al-Tusi, who appears here, is only one of many in a tradition that reaches well beyond Isaac Newton and Joseph Raphson (whose separate contributions are nicely disentangled by the authors).

The fascinating problem of computing values of pi gets a chapter here, embracing Chinese methods as well as those of Archimedes, more modern methods using infinite series, and even some of the almost bizarre feats of ingenuity that have given us many million decimal places of pi. There is a chapter on the computation of tables, and another on the numerical solution of differential equations in which Carle Runge takes pride of place. We take a trip through approximate methods for finding areas, and tests for prime numbers. Finally, indicative of a recent switch of emphasis, there is a chapter on the theoretical analysis of algorithms in the sense of recursive functions. This discusses when problems can be said to have a solution in any sense that a machine might implement, and leads to the important result that the existence of unsolvable problems can be proved.

Of course, the trichotomy with which I began is an artificial one. The production of an algorithm, in the sense of a systematic solution method, has to be accompanied by an analysis of its range, limitations and proofs of its validity. This is a far from routine taskeven though one marvels at the energy of human computers in churning out tables and other numerical results before the electronic computer came along - and the book skilfully shows the intellectual ingenuity that has been expended. Even more important, thinking algorithmically is a distinctive way of approaching mathematics, permeating the entire threefold division and not only operating at the end. Problems about squares are not quadratic equations: they were originally stated without an equation in sight. The answer is not given as a formula that one must fill up with numbers, but as a process. Today we think through problems involving large amounts of data in ways that readily allow for the incorporation of new data. It is not important to calculate more and more of pi; it is most important to use a computer quickly and accurately.

The book is remarkable for its generous quotations from original sources, which allows the discoverers to speak for themselves, and for the wealth of examples that enable us to grapple directly with the material. It has been well edited, and smoothly translated by Chris Weeks. The lonely work of mathematicians shines through and anyone interested in what mathematics really involves will enjoy it.

Jeremy Gray is in the Department of Mathematics, Open University, Milton Keynes MK7 6AA, UK. 